\title{
Uridine Metabolism in the Goldfish Retina During Optic Nerve Regeneration: Whole Retina Studies
}

\author{
Linda A. Dokas, Shinichi Kohsaka, Harry R. Burrell, and Bernard W. Agranoff \\ Neuroscience Laboratory, Mental Health Research Institute and Department of Biological Chemistry, \\ The University of Michigan, Ann Arbor, Michigan, U.S.A.
}

\begin{abstract}
Accumulation of radioactivity from $\left[{ }^{3} \mathrm{H}\right]$ uridine in incubations of whole goldfish retinas is increased in the ipsilateral retina during a period of regeneration that follows unilateral optic nerve crush. Brief incubations to investigate the nature of enhanced labeling of the acid-soluble fraction showed a peak uptake 4 days following crush, with a gradual decrease to control levels by 21 days following crush. That nucleoside uptake may not mediate the effect is supported by the observation that the rate of uptake of $5^{\prime}$-deoxyadenosine, a nonmetabolizable nucleoside analog, is the same in post-crush (PC) and normal (N) retinal incubations. Following brief incubations of $\mathrm{PC}$ and $\mathrm{N}$ retinas with $\left[{ }^{3} \mathrm{H}\right]$ uridine, there is enhanced labeling in $\mathrm{PC}$ retinas relative to $\mathrm{N}$ retinas of recovered UMP, UDP, UTP, and uridine nucleotide sugars, whereas recovery of labeled uridine itself is slightly decreased. The results suggest that the increased accumulation of radioactivity in PC retinas following incubation with uridine reflects an increase in the activities of retinal uridine kinase and uridine nucleotide kinases. Key Words: Uridine-Goldfish retina-RegenerationNucleoside kinase-Nucleotide kinase. Dokas L. A. et al. Uridine metabolism in the goldfish retina during optic nerve regeneration: Whole retina studies. $J$. Neurochem. 36, 1160-1165 (1981).
\end{abstract}

Retinal ganglion cells of many teleosts and amphibians can regenerate functional axons following optic nerve injury (for reviews, see Grafstein, 1975; Grafstein and McQuarrie, 1978). Previous work from this laboratory has shown that following optic nerve crush, there are increases in the labeling of ribosomal RNA and in RNA content (Burrell et al., 1978). Increased labeling of retinal cytoplasmic poly(A)-containing RNA, including the mRNA fraction coding for tubulin (Burrell et al., 1979) is also seen following axotomy. Although the ganglion cell layer represents only a fraction of the total retinal volume, it is believed to be the site of these alterations measured in whole retinal preparations.

Earlier studies on RNA metabolism (Burrell et al., 1978) employed 3-h incubations of intact reti-

Received August 27, 1980; accepted October 6, 1980.

Address correspondence and reprint requests to Dr. Bernard W. Agranoff, Neuroscience Laboratory Building, University of Michigan, 1103 E. Huron Ann Arbor, Michigan 48109.

The present address of Linda A. Dokas is Department of Biochemistry, Medical College of Ohio, Toledo, Ohio 43699. nas, which also indicated a possible increase in radioactivity in the acid-soluble pool. In the present studies, brief incubations of whole retina are examined to learn whether uridine uptake and/or metabolism are increased during regeneration. The results suggest that optic nerve regeneration produces enhanced activity of retinal uridine kinase and uridine nucleotide kinases.

\section{MATERIALS AND METHODS}

\section{Materials}

$\left[5-{ }^{3} \mathrm{H}\right]$ and $\left[5,6-{ }^{3} \mathrm{H}\right]$ uridine $(20-70 \mathrm{Ci} / \mathrm{mmol})$ were obtained from New England Nuclear Corporation (Boston, Massachusetts).
The present address of Harry R. Burrell is Nucleotide Division, New England Nuclear, Boston, Massachusetts 02118.

Abbreviations used: HEPES, $N$-2-hydroxyethylpiperazine$N^{\prime}$-2-ethanesulfonic acid; HVE, High voltage electrophoresis; NBTG, 6(2-Hydroxy-5-nitrobenzyl)thioguanosine; PC, Postcrush; N, Normal; TCA, Trichloroacetic acid. 
6(2-Hydroxy-5-nitrobenzyl)thioguanosine (NBTG) was purchased from Calbiochem-Behring Corp. (San Diego, California). Unlabeled 5'-deoxyadenosine was obtained from Research Plus Laboratories, Inc. (Denville, New Jersey). $\left[5^{\prime}-{ }^{3} \mathrm{H}\right] 5^{\prime}$-Deoxyadenosine was the gift of Dr. David Kessel, Department of Pharmacology, Wayne State University, Detroit, Michigan. Other chemicals were obtained from Sigma Chemical Co. (St. Louis, Missouri).

Goldfish $(6-7 \mathrm{~cm}$ body length) were obtained from Ozark Fisheries (Stoutland, Missouri), and were maintained at $20-22^{\circ} \mathrm{C}$.

\section{In Vitro Incubation of Goldfish Retinas}

Intraorbital optic nerve crush was performed as previously described (Springer and Agranoff, 1977). The right optic nerve was crushed while the left retina of each fish served as the control. Post-crush (PC) and control (normal, N) retinas were removed from 5-40 goldfish, treated with hyaluronidase, and incubated with $2 \mu \mathrm{Ci}$ of $\left[{ }^{3} \mathrm{H}\right.$ ] uridine per retina in $5 \mathrm{ml}$ of a HEPES-salts-glucose medium (Dunlop et al., 1974). Pre-treatment of the retinas with hyaluronidase (Burrell et al., 1978) removed adhering vitreous that might otherwise have retained the labeled precursor. Incubations were terminated by chilling on ice and addition of $1.5 \mathrm{ml}$ of cold $0.86 \%$ saline containing $10^{-4} \mathrm{M}-\mathrm{NBTG}$ to inhibit further nucleoside transport (Paterson and Oliver, 1971; Paterson et al., 1977). Retinas were rinsed several times in cold salineNBTG and then in saline containing $5 \mathrm{~mm}$-uridine.

\section{Electrophoretic Separation of Nucleosides and Nucleotides}

Fifteen to twenty-five $\mathrm{PC}$ or $\mathrm{N}$ goldfish retinas, incubated and washed as described above, were homogenized in $10 \mathrm{ml}$ of cold, $10 \%$ trichloracetic acid (TCA), using a motor-driven, Teflon-glass homogenizer. The suspension was centrifuged at $12,000 \times g$ for $10 \mathrm{~min}$. The pellet was washed twice with $3 \mathrm{ml}$ of cold $10 \%$ TCA and the supernatant washes were combined.

TCA-soluble fractions were shaken four times with an equal volume of ether and then lyophilized. Residues were redissolved in 100-200 $\mu \mathrm{l}$ of water, and a portion of each sample was counted for radioactivity in a Tritontoluene scintillant. To separate the component radioactive substances, an aliquot of 5-30 $\mu$ l of each sample was applied to premoistened Whatman No. 1 paper with 200 $\mu \mathrm{g}$ each of unlabeled uridine, UMP, UDP-glucose, UDP, and UTP as carrier, and electrophoresed at 4,000 V for 30 $\mathrm{min}$ in $0.06 \mathrm{M}$-sodium oxalate buffer ( $\mathrm{pH} 1.5$ ). These conditions separated the standards, except UDP and UDPglucose. The latter were well separated by high voltage electrophoresis (HVE) in a pyridine acetate buffer ( $\mathrm{pH}$ 4.3; pyridine-acetic acid-water; 14:40:356). Material comigrating with UDP-glucose was not further identified. The pyridine-acetate system separated all of the standards except UDP and UTP, which traveled as a single spot, as visualized under ultraviolet (UV) light. Separated nucleotides were visualized following a light ammonium molybdate spray and UV irradiation (Bandurski and
Axelrod, 1951). Appropriate regions were cut out, combusted in a Packard Model 306 sample oxidizer, and counted by scintillation techniques. Over $90 \%$ of the radioactivity from a $\left[{ }^{3} \mathrm{H}\right]$ UTP standard added to unlabeled retinas prior to homogenization in TCA was recovered in the UTP spot following separation in the sodium oxalate system. TCA-insoluble fractions were dissolved in $1 \mathrm{ml}$ of Soluene-350 (Packard Instrument Co., Inc., Downers Grove, Illinois) and a portion of each sample was counted in ACS scintillant (Amersham Corporation, Arlington Heights, Illinois).

\section{Incubation with 5'-Deoxyadenosine}

$\left[5^{\prime}-{ }^{3} \mathrm{H}\right] 5^{\prime}$-Deoxyadenosine was purified by TLC as described by Kessel (1978). Groups of five PC or $\mathrm{N}$ retinas were incubated in $2 \mathrm{ml}$ of the HEPES-salts-glucose medium containing $1.0 \mu \mathrm{Ci}$ per retina of the purified material together with unlabeled carrier to give a final concentration of $10^{-4} \mathrm{M}$. Following incubation at $25^{\circ} \mathrm{C}$ for 5 min, 3 vol. of chilled $150 \mathrm{~mm}-\mathrm{NaCl}$ containing $2 \mathrm{~mm}$ $\mathrm{HgCl}_{2}$ and $2 \mathrm{~mm}-\mathrm{NaI}$ was added to block further movement of the nucleoside across the membrane in either direction (Levine and Stein, 1966; Lieu et al., 1971). Retinas were rinsed once in this solution and were then homogenized in $2 \mathrm{ml}$ of cold $10 \%$ TCA. The TCA-soluble fraction, prepared as described above, was counted in a toluene scintillation cocktail containing $26 \%$ Triton.

\section{RESULTS}

\section{Uridine Incorporation}

Ten-minute incubations of 4-day $\mathrm{PC}$ and $\mathrm{N}$ retinas indicated a significant increase in uridine uptake in both acid-soluble and -insoluble fractions (Table 1). A lesser increase of accumulation into the two fractions was seen in 8-day PC retinas. There was no significant change in either fraction of $\mathrm{N}$ retinas at either times.

Since a peak of incorporation had previously been found at 8 days PC in $3 \mathrm{~h}$ incubations (Burrell et al., 1978), these parameters were re-examined. The results indicate (Table 1), as previously observed, that the PC: $N$ ratios from the longer incubations were higher at 8 days PC than at 4 days. As noted previously, the increase in total RNA labeling under conditions in which the precursor pool radioactivity is limiting may not accurately reflect the rate of RNA labeling. The increase in RNA labeling at 8 days $P C$ in the present experiment may, in fact, be attributable to an apparent decrease in $N$ retinal RNA labeling rather than to an increase in $\mathrm{PC}$ radioactivity. The results indicate that the 3-h incubation periods used in earlier experiments to maximize yields of labeled RNA did not permit detection of an earlier and greater enhancement of incorporation of precursor into the acid-soluble fraction that is present 4 days PC. 
TABLE 1. Enhanced uridine utilization by post-crush retinas following nerve crush

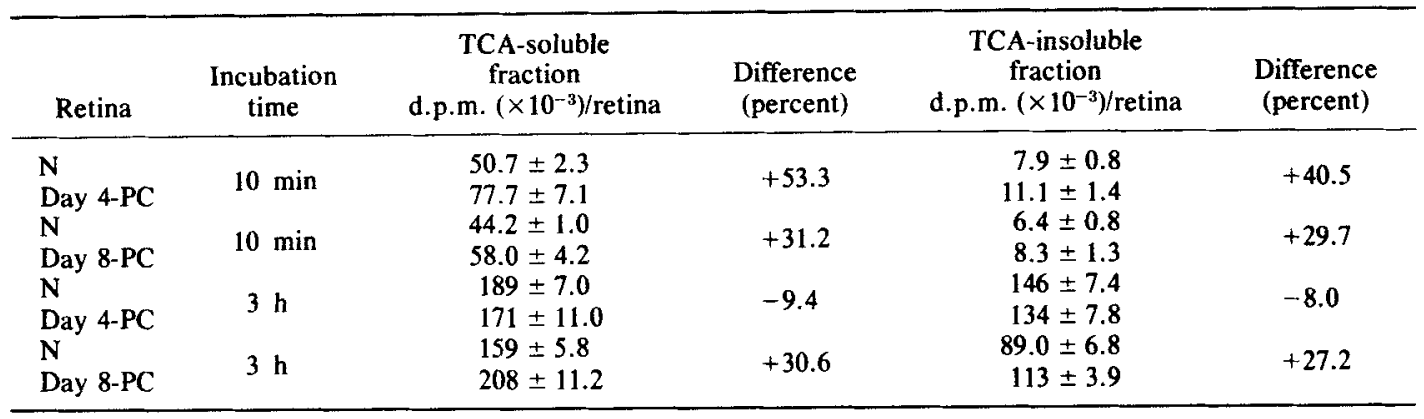

Groups of five normal (N) or post-crush (PC) retinas were incubated for either 10 min or $3 \mathrm{~h}$ in a HEPES-salts glucose medium with $2 \mu \mathrm{Ci}$ of $\left[{ }^{3} \mathrm{H}\right]$ uridine per retina. Labeling of the RNA precursor (TCA-soluble) and RNA (TCA-insoluble) fractions was measured as described in Materials and Methods. Values are the mean \pm S.E.M. of three separate incubations of $\mathrm{N}$ or $\mathrm{PC}$ retinas. Percent difference was calculated as $(\mathrm{PC}-\mathrm{N} / \mathrm{N} \times 100)$.

\section{Time Course of Enhanced Uridine Accumulation and Incorporation into RNA During Optic Nerve Regeneration}

The accumulation of $\left[{ }^{3} \mathrm{H}\right]$ uridine and incorporation into RNA was further examined in 10-min incubations of whole retinas removed at various times following optic nerve crush (Fig. 1). A small, suggestive increase was seen by day 2 , and maximal elevation of labeling of $P C$, relative to $N$ retinas occurred at 4 days following crush, and decreased slowly thereafter.

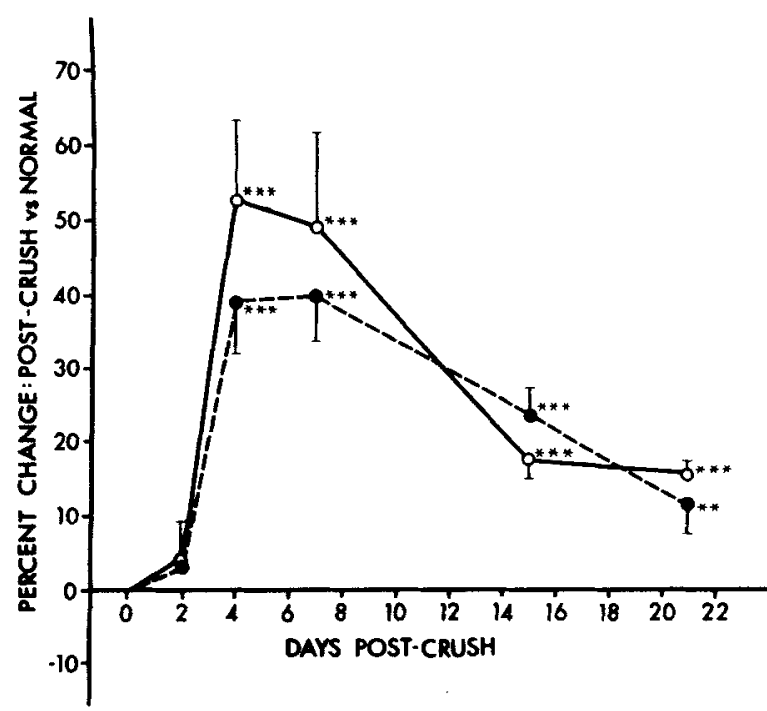

FIG. 1. Comparison of $\left[{ }^{3} \mathrm{H}\right]$ uridine uptake and incorporation into RNA by post-crush (PC) and normal (N) retinas during optic nerve regeneration. Retinas were incubated for $10 \mathrm{~min}$ at $25^{\circ} \mathrm{C}$ in a HEPES-salts-glucose medium containing $2 \mu \mathrm{Ci}$ of $\left[{ }^{3} \mathrm{H}\right]$ uridine per retina. Each point represents the percent change in d.p.m. per retina obtained from homogenates of three groups of five normal or five post-crush retinas. Normal retinal values are as given in Table 1. Statistical significance is indicated as **P<0.01; ${ }^{* * *} P<0.005 . O-O$, TCA-soluble fraction; - - - TCA-insoluble fraction (RNA).

\section{Uptake of $\left[{ }^{3} \mathrm{H}\right] 5^{\prime}$-Deoxyadenosine}

To determine whether nucleoside transport per se is regulated in the retina during optic nerve regeneration, we made use of $5^{\prime}$-deoxyadenosine. $\mathrm{PC}$ and $\mathrm{N}$ retinas (either 3 or 8 days following nerve crush) were incubated with $1 \mu \mathrm{Ci}$ of $\left[5^{\prime}-{ }^{3} \mathrm{H}\right] \mathrm{S}^{\prime}$-deoxyadenosine per retina with sufficient unlabeled carrier to give a final concentration of $10^{-4} \mathrm{M}$, near the reported $K_{\mathrm{m}}\left(1.15 \times 10^{-4} \mathrm{M}\right)$ for its transport (Kessel, 1978). This concentration of $5^{\prime}$-deoxyadenosine minimized the contributions to the total recovered radioactivity from both nonspecific binding and from the diffusion component of its transport (Kessel, 1978). Table 2 shows that whole PC and N retinas accumulate $\left[{ }^{3} \mathrm{H}\right]$ deoxyadenosine from the extracellular medium to the same extent.

\section{Distribution of Radioactivity Following [ $\left.{ }^{3} \mathbf{H}\right]$ Uridine Uptake}

The nature of labeled substances found in normal goldfish retina 5 min following incubation with

TABLE 2. Uptake of $\left[5^{\prime}-{ }^{3} \mathrm{H}\right] 5^{\prime}$-deoxyadenosine by the goldfish retina in vitro

\begin{tabular}{lcc}
\hline Retina & $\begin{array}{c}\text { Uptake of }\left[{ }^{3} \mathrm{H}\right] 5^{\prime}- \\
\text { deoxyadenosine } \\
\text { d.p.m. }\left(\times 10^{-3}\right) \text { per } \\
\text { five retinas }\end{array}$ & $\begin{array}{c}\text { Difference } \\
\text { (percent) }\end{array}$ \\
\hline N & $254 \pm 8.9$ & $-0.3 \pm 4.6$ \\
Day 3-PC & $254 \pm 17.3$ & $(P<0.45)$ \\
N & $246 \pm 21.8$ & $+4.6 \pm 5.4$ \\
Day 8-PC & $259 \pm 33.9$ & $(P<0.20)$ \\
\hline
\end{tabular}

Three or four groups of five normal $(\mathrm{N})$ and 3- or 8-day postcrush (PC) retinas were incubated for $5 \mathrm{~min}$ at $25^{\circ} \mathrm{C}$ in $2.0 \mathrm{ml}$ of a HEPES-salts-glucose medium containing $1 \mu \mathrm{Ci}$ of $\left[{ }^{3} \mathrm{H}\right] 5^{\prime}-$ deoxyadenosine $\left(10^{-4} \mathrm{M}\right)$ per retina. The assay was terminated and the retinal TCA-soluble fraction was prepared as described in Materials and Methods. Values are the mean \pm S.E.M. 
$\left[{ }^{3} \mathrm{H}\right]$ uridine is shown in Fig. 2. Approximately $95 \%$ of the recovered radioactivity was acid-soluble. No measurable radioactivity was associated with cytidine or its nucleotides in retina, although longer incubation periods resulted in significant labeling of cytidine compounds as well as an increase in the percentage of total radioactivity associated with the acid-insoluble fraction. No radioactivity was detected in purine nucleosides or nucleotides isolated from either TCA-soluble or -insoluble fractions.

The distribution pattern is altered following crush (Fig. 3). Eight-day PC retinas incubated for $5 \mathrm{~min}$ with $\left.{ }^{3} \mathrm{H}\right]$ uridine as described in Fig. 2 show significantly greater incorporation of radioactivity into TCA-soluble material and into RNA than do $\mathrm{N}$ retinas and reflect enhanced labeling of all of the uridine nucleotides. However, significantly less radioactivity co-migrates with $\left[{ }^{3} \mathrm{H}\right]$ uridine in $\mathrm{PC}$, compared with $\mathrm{N}$ retinas. Nucleotide analysis of the RNA hydrolysates from 5-min incubations showed that nearly all ( $>95 \%$ ) of the radioactivity found in TCA-insoluble form in PC retinas was present in uridine nucleotide.

\section{DISCUSSION}

Cells undergoing a growth response accumulate various RNA precursors (for reviews, see Plage-

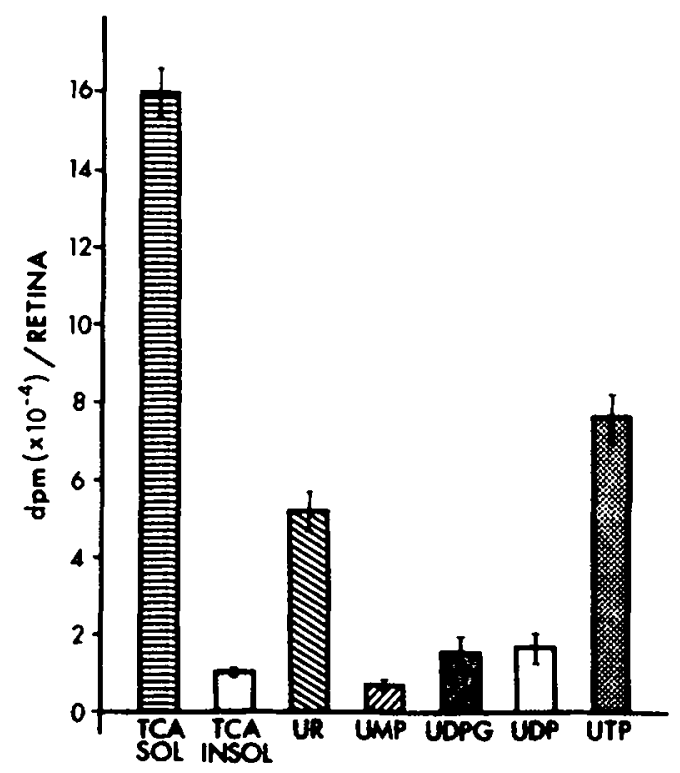

FIG. 2. In vitro metabolism of $\left[{ }^{3} \mathrm{H}\right]$ uridine by whole goldfish retinas. Groups of 35-40 normal goldfish retinas were incubated for $5 \mathrm{~min}$ at $25^{\circ} \mathrm{C}$ in $5 \mathrm{ml}$ of a HEPES-salts-glucose medium containing $2 \mu \mathrm{Ci}$ of $\left[{ }^{3} \mathrm{H}\right]$ uridine per retina. Following homogenization in 10\% TCA, soluble and insoluble fractions were measured for radioactivity. The TCA-soluble fraction was further characterized by HVE. Each column represents the average value \pm S.E.M. Obtained from six individual experiments. TCA SOL, TCA-soluble fraction; TCA INSOL, TCA-insoluble fraction; UR, uridine plus uracil; UDPG, uridine 5'-dlphospho-sugars (co-migrating with UDPglucose). mann and Richey, 1974; Levine et al., 1974). The regenerating goldfish visual system serves as a further example. We have previously demonstrated (Burrell et al., 1978) that the axotomized goldfish retina accumulates acid-soluble radioactivity following incubation with $\left[{ }^{3} \mathrm{H}\right]$ uridine. In the previous experiments, retinas were incubated for $3 \mathrm{~h}$ in vitro with $\left[{ }^{3} \mathrm{H}\right]$ uridine, in order to ensure sufficient incorporation of radioactivity for analysis of RNA fractions. The time of incubation was shortened in the present study to provide a more reliable measure of nucleoside uptake and metabolism. Specific activities of the nucleotide triphosphate pools in the nuclei of ganglion cells would be useful for the calculation of enhanced RNA synthesis that, e.g., underlies the formation of new tubulin during axonal regrowth (Heacock and Agranoff, 1976; Burrell et al., 1978, 1979). The present isotopic studies do not, however, provide information regarding chemical amounts of the various labeled products.

The development of enhanced uridine accumulation during optic nerve regeneration corresponds well with the time course of appearance of reduced silver grains from injected $\left[{ }^{3} \mathrm{H}\right]$ uridine over retinal ganglion cells, following optic nerve axotomy, as reported by Murray (1973). Since the ganglion cells are believed to mediate the observed increase in nucleic acid metabolism and represent only $5 \%$ of the total retinal cell mass (Murray and Grafstein,

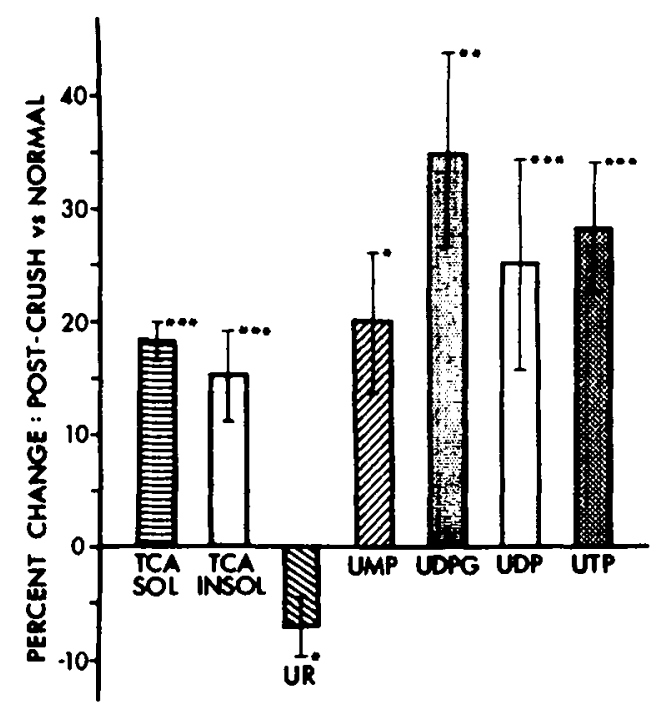

FIG. 3. Comparison of $\left[{ }^{3} \mathrm{H}\right]$ uridine uptake and incorporation into both RNA and uridine nucleotides by 8 days post-crush (PC) and normal $(N)$ retinas, following incubation as described in Fig. 1. Each column represents the percent change in d.p.m. $\times 10^{-4}$ per retina obtained from homogenates of six groups of PC, as compared with $\mathrm{N}$ retinas. The d.p.m./retina values for each fraction from $\mathrm{N}$ retinas are given In Fig. 1. Abbreviations are given in the legend to Fig. 1. Statistical significance is shown as ${ }^{*} P<0.05 ;^{* * P}<0.01 ; \cdots * P$ $<0.005$. 
1969), the $50 \%$ enhancement in uridine metabolism could reflect more than 10 -fold stimulation in ganglion cell nucleoside kinase activities.

The observed enhanced accumulation of radioactivity might have resulted from increased uptake of uridine from the extracellular medium and/or by enhanced metabolic trapping, i.e., intracellular phosphorylation of uridine. In the present study we have shown that 5 '-deoxyadenosine, a nucleoside that can enter cells but is not phosphorylated (Kessel, 1978), was taken up equally by $\mathrm{N}$ and $\mathrm{PC}$ retinas. Our previous studies (Burrell et al., 1978) demonstrated enhanced uptake of both uridine and adenosine by $\mathrm{PC}$ retinas. If we can infer from this that purine and pyrimidine metabolisms are similarly affected, the results with 5'-deoxyadenosine suggest that the transport of nucleosides across the retinal cell membrane is not measurably affected by the nerve crush. Results of recent studies with retinal cell-free preparations support the argument that enhanced uridine accumulation in fact depends on alterations in retinal uridine and uridine nucleotide kinase activities (Kohsaka et al., 1981). In a relevant study, Langford et al. (1980) reported a stimulation of RNA precursor uptake into the rat nodose ganglion following injury to the cervical vagus nerve. They found a maximal increase in uridine uptake of about $+120 \%$ at 2 days PC. The increase was attributed to increased intracellular pool size.

Increases in uridine uptake has been most thoroughly studied in a number of in vitro systems. NGF stimulates uptake of RNA precursors into dorsal root ganglion cells (Horii and Varon, 1977). In $3 \mathrm{~T} 3$ cells, the rate of nucleoside phosphorylation appears to account for the enhanced uptake of uridine seen on the addition of serum (Rozengurt et al., 1977; Koren et al., 1978). Using 2-deoxyglucose, Goldenberg and Stein (1978) varied the intracellular ATP concentration of 3T3 cells and determined that the enhanced phosphorylation of uridine seen when these cells are stimulated results from a decrease in the $K_{\mathrm{m}}$ of uridine kinase for ATP. The intracellular proportion of multiple forms of uridine kinase varies with functional state (Krystal and Scholefield, 1973; Keefer et al., 1975). As Novikoff hepatoma cells develop resistance to the anti-tumor drug, 5-azacytidine, they display a transient increase in uridine kinase II, which possesses a lowered $\boldsymbol{K}_{\mathrm{m}}$ for uridine and a decreased affinity for 5-azacytidine (Keefer et al., 1975).

While the present studies would appear to minimize the importance of uridine transport, Plagemann and Richey (1974) have argued that a number of cell types possess a greater capacity for substrate phosphorylation than for the transport of substrate into the cell, and that the transport must in these cases be rate-limiting. Furthermore, a number of substances that inhibit intracellular RNA precursor accumulation (persantin, cytochalasin B, and p-chloromercuribenzoate) have no effect on related cellular kinase activities.

Enhancement of retinal uridine and uridine nucleotide kinase activities occurs during a period of rapid metabolism (4-21 or more days $P C$ ) when a large and sustained rate of RNA synthesis can generally be anticipated for the regenerative process (Murray, 1973; Burrell et al., 1978), which includes increased transport of RNA down the regenerating optic nerve axon (Ingoglia et al., 1973; Ingoglia, 1978). The rapid initiation of the increase in labeled nucleotides following axotomy suggests it plays a critical role in the regulation of optic nerve regeneration. Further characterization of the biochemical mechanism that produces enhanced uridine metabolism in the PC retina may have direct relevance as to the nature of the primary events that initiate the process of nerve regeneration.

\section{ACKNOWLEDGMENTS}

This work was supported by NIMH grant NS 13743. L. A. D and H. R. B were postdoctoral trainees of NIMH Interdisciplinary Training grant MH 013831. S. K. was supported by the Fukuzawa Memorial Grant of Keio University, Tokyo, Japan. The authors are grateful to Marianne Andrews for her excellent technical assistance and to Dr. David Kessel for the gift of $\left[{ }^{3} \mathrm{H}\right] 5^{\prime}$-deoxyadenosine and useful discussions.

\section{REFERENCES}

Bandurski R. S. and Axelrod B. (1951) The chromatographic identification of some biologically important phosphate esters. J. Biol. Chem. 193, 405-410.

Burrell H. R., Dokas L. A., and Agranoff B. W. (1978) RNA metabolism in the goldfish retina during optic nerve regeneration. J. Neurochem. 31, 289-298.

Burrell H. R., Heacock A. M., Water R. D., and Agranoff B. W. (1979) Increased tubulin messenger RNA in the goldfish retina during optic nerve regeneration. Brain Res. 168, 628-632.

Dunlop D. S., Van Elder W., and Lajtha A. (1974) Measurement of rates of protein synthesis in rat brain slices. $J$. Neurochem. 22, 821-830.

Goldenberg G. J. and Stein W. D. (1978) Stimulation of uridine uptake in 3T3 cells is associated with increased ATP af finity of uridine-phosphorylating system. Nafure 274, 475-477.

Grafstein B. (1975) The nerve cell body response to axotomy. Exp. Neurol. 48, 32-51.

Grafstein B. and McQuarrie I. G. (1978) Role of the nerve cell body in axonal regeneration, in Neuronal Plasticity (Cotman C. W., ed), pp. 155-195. Raven Press, New York.

Heacock A. M. and Agranoff B. W. (1976) Enhanced labeling of a retinal protein during regeneration of optic nerve in goldfish. Proc. Natl. Acad. Sci. USA 73, 828-832.

Horii Z-I. and Varon S. (1977) Nerve growth factor action on membrane permeation to exogenous substrates in dorsal root ganglionic dissociates from the chick embryo. Brain Res. 124, 121-133. 
Ingoglia N. A. (1978) The effect of intraocular injection of cordycepin on retinal RNA synthesis and on RNA axonally transported during regeneration of the optic nerves of goldfish. J. Neurochem. 30, 1029-1039.

Ingoglia N. A., Grafstein B., McEwen B. S., and McQuarrie I. G. (1973) Axonal transport of radioactivity in the goldfish optic system following intraocular injection of labeled RNA precursors. J. Neurochem. 20, 1605-1615.

Keefer R. C., McNamara D. J., Schumm D. E., Billmire D. F., and Webb T. E. (1975) Early temporal changes in the uridine kinase isozyme profile of the Novikoff hepatoma in response to 5'-azacytidine treatment. Biochem. Pharmacol. 24, 1287-1290.

Kessel D. (1978) Transport of a nonphosphorylated nucleoside, $S^{\prime}$-deoxyadenosine, by murine leukemia $\mathrm{L} 1210$ cells. $J$. Biol. Chem. 253, 400-403.

Kohsaka S., Dokas L. A., and Agranoff B. W. (1981) Uridine metabolism in the goldfish retina during optic nerve regeneration: Cell-free preparations. J. Neurochem. 36, 1166-1174.

Koren R., Shohami E., Bibi O., and Stein W. D. (1978) Uridine transport of properties of mammalian cell membranes are not directly involved with growth control or oncogenesis. FEBS Lett. 86, 71-75.

Krystal G. and Scholefield P, G. (1973) The partial purification and properties of uridine kinase from Ehrlich ascites tumor cells. Can. J. Biochem. 51, 379-389.

Langford C. J., Scheffer J. W., Jeffrey P. L., and Austin L. (1980) The in vitro synthesis of RNA within the rat nodose ganglion following vagotomy. J. Neurochem. 34, 531-539.
Levine M. and Stein W. D. (1966) The kinetic parameters of the monosaccharide transfer system of the human erythrocyte. Biochim. Biophys. Acta 127, 179-193.

Levine R. L., Hogenraad N. J., and Kretchmer N. (1974) A review: Biological and clinical aspects of pyrimidine metabolism. Pediatr. Res. 8, 724-734.

Lieu T. S., Hudson R. A., Brown R. K., and White B. C. (1971) Transport of pyrimidine nucleosides across human erythrocyte membranes. Biochim. Biophys. Acta 241, 884-893.

Murray M. (1973) [ $\left.{ }^{3} \mathrm{H}\right]$ Uridine incorporation by regenerating retinal ganglion cells of goldfish. Exp. Neurol. 39, 489-497.

Murray M. and Grafstein B. (1969) Changes in the morphology and amino acid incorporation of regenerating goldfish optic neurons. Exp. Neurol. 23, 544-560.

Paterson A. R. P. and Oliver J. M. (1971) Nucleoside transport. II. Inhibition by $p$-nitrobenzylthioguanosine and related compounds. Can. J. Biochem. 49, 271-274.

Paterson A. R. P., Naik S. R., and Cass C. E. (1977) Inhibition of uridine uptake in hela cells by nitrobenzylthioinosine and related compounds. Mol. Pharmacol. 13, 1014-1023.

Plagemann P. G. W. and Richey D. P. (1974) Transport of nucleosides, nucleic acid bases, choline and glucose by animal cells in culture. Biochim. Biophys. Acta 344, 265-305.

Rozengurt E., Stein W. D., and Wigglesworth N. M. (1977) Uptake of nucleosides in density-inhibited cultures of 3T3 cells. Nature 267, 442-444.

Springer A. D. and Agranoff B. W. (1977) Effect of temperature on rate of goldfish optic nerve regeneration: A radioautographic and behavioral study. Brain Res. 128, 405-415. 